Published as Bell, K. and Salmon, A. (2010) What women who use drugs have to say about ethical research: Findings of an exploratory qualitative study. JERHRE: Journal of Empirical Research on Human Research Ethics, 6(4): 84-98. Copyright (C) 2010 by Joan Sieber. Copying and permissions notice: Authorization to copy this content beyond fair use (as specified in Sections 107 and 108 of the U. S. Copyright Law) for internal or personal use, or the internal or personal use of specific clients, is granted by the University of California Press on behalf of Joan Sieber for libraries and other users, provided that they are registered with and pay the specified fee via Rightslink ${ }^{\circledR}$ on Caliber (http://caliber.ucpress.net/loi/jer) or directly with the Copyright Clearance Center, http://www.copyright.com.

\title{
What Women Who Use Drugs HaVe to SAY ABOUt ETHICAL RESEARCH: FINDINGS OF AN EXPLORATORY QUALITATIVE STUDY
}

\section{KIRSTEN BELL AND AMY SALMON}

\begin{abstract}
:
Drug users are generally seen as a vulnerable population requiring special protection in research; however, to date there has been little empirical research into the ethics of research with illicit drug users. Moreover, the available research has tended to treat 'drug users' as a homogenous category, and fails to consider potential gender differences in users' experiences. Drawing on focus groups with twenty-seven female drug users in Vancouver, Canada, this study examines women's experiences of research and what they see as ethical and respectful engagement. Many study participants talked about feeling dehumanized as a result of prior research participation. Women were critical of the assumption that drug users lack the capacity to taken part in research, and affirmed the appropriateness of financial incentives. A variety of motivations for research participation were identified, including a desire for financial gain and altruistic concerns such as a desire to help others. These findings suggest that women drug users' views on ethical research differ from prevailing assumptions amongst institutional review boards about how research with such populations should proceed.
\end{abstract}




\section{Introduction}

Ethicists and institutional review boards ${ }^{1}$ frequently raise concerns about the potential for exploitation of 'vulnerable populations' in research and emphasize the need for 'special protection'2 of such groups in research and clinical settings (Office for Human Research Protections, 2009; CIHR, NSERC \& SSHRC, 2010). Although not specifically referenced in North American research ethics guidelines, drug users are generally seen to constitute one such 'vulnerable population' (Fisher, 2004; Anderson \& DuBois, 2007). As Anderson and DuBois (2007: 9) note, "individuals with substance abuse problems can be considered vulnerable insofar as their addictions contribute to or accompany economic hardship, comorbid psychiatric or cognitive disorders, social stigmatization, and incarceration or other involvement in the legal system".

Concerns about the vulnerability of drug users in the context of research participation generally center on several distinct, albeit interrelated, issues. First, questions have been raised about the capacity of drug users to consent to research participation. There has been considerable debate about whether 'addicts' who are not seeking treatment for their addiction are capable of providing informed consent (Carter \& Hall, 2008) and some have suggested that the essential features of craving and denial preclude the degree of rationality required for research participation (e.g., Cohen, 2002). Other areas of discussion and debate include the effects of temporary impairments stemming from acute intoxication or withdrawal and more permanent cognitive deficits associated with the long-term use of psychoactive substances (see McCrady \& Bux, 1999; Fisher, 2004; Festinger et al., 2007; Loue \& Ioan, 2007).

Second, the ethics of monetary payments in research are hotly debated within the broader bioethics literature (e.g., Lemmens \& Elliot, 1999; Chambers, 2001; Grady, 2001; Moreno, 2001; Todd, 2001; Vanderpool, 2001), and specific concerns have been raised about the use of financial incentives in research with drug users. Key issues identified include the idea that such payments jeopardize informed consent by acting as an undue inducement, exploiting drug users' economic vulnerability and marginalization; some have also argued that paying drug users encourages and rewards illicit drug use (Fry \& Dwyer, 2001; Buchanan et al., 2002; Ritter et al., 2002; Sheldon, 2005; Fry et al., 2005, 2006).

Another concern raised in the literature relates to confidentiality and privacy issues (McCrady \& Bux, 1999; Fisher, 2004; Anderson \& DuBois, 2007). In light of the illegality of illicit drug use and the penalties associated with its disclosure, this is an area that drug users themselves are often deeply concerned about. ${ }^{3}$ Moreover, although researchers may promise drug users confidentiality, mandatory reporting requirements relating to disclosures of child neglect and endangerment mean that researchers cannot always keep this promise - something often not adequately disclosed to participants (McCrady \& Bux, 1999).

Clearly, research with drug users entails very real ethical issues that require careful consideration on the part of researchers and institutional review boards. In light of these issues, it is unsurprising that applications for institutional ethics approval submitted by addictions researchers often undergo intense scrutiny. However, anecdotal evidence suggests that review boards' zeal in their application of ethics guidelines to drug research is partially due to over-protectionist attitudes (Anderson \& DuBois, 2007). Unfortunately, 
these attitudes are often formed without an adequate understanding of the realities of drug use and rely to some extent on prevailing stereotypes that depict drug users as selfish, irresponsible and unable to make sound judgments (Ritter et al., 2002).

The limited available empirical research into drug users' understanding and experiences of research suggests that the concerns of institutional review board members about the capacity issues of drug users and the potential coerciveness of financial incentives are overstated (Anderson \& DuBois, 2007). Ironically, concerns expressed in the name of protecting drug users may actually harm individuals by inhibiting research that is beneficial to them and their communities or disallowing study procedures that participants themselves endorse as ethical and respectful (Fisher, 2004: 92; Burris \& Moss, 2006: 52; Anderson \& DuBois, 2007: 102).

Although these studies have provided important insights into the experiences of drug users and their motivations for taking part in research, a limitation of existing research is the tendency to treat 'drug users' as a generic category, erasing the gendered dimensions of prevailing discourses on illicit drug use, where women are constructed as distinctively vulnerable and 'at risk' (see Campbell, 2000). Thus, although available studies on drug users' research experiences generally include both men and women, results are often aggregated in such a way that it is unclear whether potential gender differences were considered or explored (e.g., Festinger et al., 2005, 2007; Slomka et al., 2007).

While male and female illicit drug users share much in common, there are some important differences in the patterns and context of their drug use; for example, men are more likely to finance drug use through criminal activity than women (Powis et al., 1996) and women are more likely to engage in sex work (Miller, 1995; Maher, 1997). Moreover, there are some differences in the types of research that male and female drug users take part in, with women more likely to participate in studies examining maternal substance use (e.g., Lam et al., 2004; Banwell \& Bammer, 2006) or trauma, violence and abuse (e.g., Boyd, 1993; Fullilove et al., 1993; Najavits, 1997; Madrano et al., 1999).

In light of calls for an explicit consideration of gender in health research and policy (Krieger, 2003; Salmon et al., 2006), addictions researchers, including those interested in developing evidence-based research ethics for studies with this population, can no longer afford to ignore gender. Thus, while there is clearly an urgent need to ensure that the voices of drug users are factored into discussions about the ethics of research conducted with them (Fisher, 2004), there is an equally urgent need for research that recognizes potential differences in the voices of drug users. To this end, this paper reports key findings from an exploratory focus group study conducted in Vancouver, Canada, in 2008 with women who use illicit drugs. This study emerged out of long-term relationships the research team had with substance-using women, service providers and peer advocacy organizations and aimed to learn more about women's prior research experiences ${ }^{4}$ and what they consider to be ethical and respectful research.

\section{Methods}

POPULATION AND SETTING

To be included in this study, participants had to: (1) self-identify as women, (2) be at least 19 years of age, ${ }^{5}$ (3) have past or current experiences of problematic illicit drug use or 
addiction, and (4) have participated in some form of health research in the past (i.e. individual interviews, focus groups, providing biological specimens, clinical trials, paper surveys, longitudinal/cohort studies, program evaluations, etc.).

TABLE 1. Characteristics of study participants

\begin{tabular}{|c|c|c|}
\hline $\begin{array}{l}\text { Partner } \\
\text { organization }\end{array}$ & $\begin{array}{l}\text { Number of } \\
\text { participants }\end{array}$ & Characteristics of participants \\
\hline Aurora Centre & 7 & $\begin{array}{l}\text { - } \text { Currently receiving addictions treatment } \\
\text { - } \quad \text { Ourrently abstaining from illicit drug use } \\
\text { - } \quad \text { Prior research experience primarily with studies } \\
\text { evaluating the Centre's treatment program }\end{array}$ \\
\hline $\begin{array}{l}\text { BC Coalition of } \\
\text { Experiential } \\
\text { Women }\end{array}$ & 6 & $\begin{array}{l}\text { - } \text { Connected to Downtown Eastside (DTES) } \\
\text { - } \text { Community } \\
\text { - } \quad \text { Biologically female or transgendered } \\
\text { - } \text { Over } 19 \text { years of age } \\
\text { - } \quad \text { Prior research experience primarily with non- } \\
\text { intervention studies and PAR/CBR studies }\end{array}$ \\
\hline VANDU & 10 & $\begin{array}{l}\text { - } \quad \text { Connected to DTES community } \\
\text { - Included self-identified Aboriginal women } \\
\text { - } \text { Ovcluded HIV+ participants } \\
\text { - } 19 \text { years of age } \\
\text { PAior research experience in a variety of } \\
\text { between VANDU and researchers }\end{array}$ \\
\hline Watari & 4 & $\begin{array}{l}\text { - } \quad \text { Connected to DTES community } \\
\text { - } \quad \text { Aged between 19-24 } \\
\text { - } \quad \text { Street involved } \\
\text { intervention studies } \\
\text { interion primarily with non- }\end{array}$ \\
\hline
\end{tabular}

Participants were recruited through posters and study announcements at four partner organizations located in Vancouver, Canada: the Aurora Centre at BC Women's Hospital (an alcohol and drug residential and day treatment for women), the BC Coalition of Experiential Women (BCCEW, a peer-based advocacy organization for women in the sex trade), the Vancouver Area Network of Drug Users (VANDU) Women's Group (a peer-based support and advocacy organization for current and former illicit drug users), and Watari Youth and Family Alcohol and Drug Counseling Service. These agencies were chosen to capture the diversity of experiences among women who use illicit drugs (e.g., women seeking treatment for their substance use, women not seeking treatment but advocating for harm reduction, women in the sex trade and young women) and to build on established relationships research team members had developed with women, health and social service providers, and peer-driven organizations.

Twenty-seven women participated in 4 focus groups: 7 at the Aurora Centre focus group, 6 at the BCCEW focus group, 10 at the VANDU focus group and 4 at the Watari focus group 
(see table 1). All of the participants had experienced periods of stability in the context of their substance use, were involved in organizations and formal or informal support networks, and took part in a variety of self/collective advocacy efforts in their communities. Participants had primarily taken part in non-intervention research, including surveys, interviews and focus-group studies, although some women in the VANDU focus group (especially those who identified as $\mathrm{HIV+}$ ) had taken part in clinical studies such as longitudinal randomized drug trials. Women in the VANDU and BCCEW focus groups also had experience with community-based research (CBR) and participatory-action research (PAR) projects and women in the Aurora Centre focus group had prior experience of program evaluations, which are routinely administered to clients enrolled in the Centre's addictions treatment program.

\section{DESIGN}

Focus groups were the primary data collection method chosen for the study. As feminist social scientists and women's health researchers have noted, group interviews are potent mechanisms for generating high quality, interactive data consistent with the development of emergent hypotheses (Kitzinger, 1994; Harrison \& Barlow, 1995; Wilkinson, 1998). The dynamic nature of group conversations was harnessed to allow for preliminary analysis of women's experiences (Ristock \& Pennell, 1996; Salmon, 2007). Through their involvement in the focus groups, participants had an opportunity to share their individual experiences with others in the group and to become engaged in identifying recommendations to better serve female drug users participating in research.

Due to the marginalized and stigmatized status of women who use illicit substances, focus group facilitators were chosen based on their relationship to partner agencies and their experience working with women who use drugs. ${ }^{6}$ All focus groups (except for the Watari group) were facilitated by a member of the research team who had an established relationship with the community partner agency and had direct experience with the issues and concerns that might arise there but was not involved in the direct provision of service to clients. A research assistant who was a member of the research team but who had no established relationship with Watari or its clients facilitated the focus group at this organization. The study was reviewed and approved by the University of British Columbia Behavioural Research Ethics Board and by the Children's and Women's Hospital Research Ethics Board.

\section{PROCEDURES}

Following the circulation of a study advertisement at the four partner organizations, women interested in taking part in the study contacted the focus group facilitator, who screened them to determine whether they met the inclusion criteria. ${ }^{7}$ All women deemed eligible to participate in this study were provided with the following at least 1 week prior to the focus group: 1) time and location of focus groups occurring in their community; 2) the name and contact information for the focus group facilitator(s); and 3) a copy of the project's consent form. Before each focus group, the facilitator orally reviewed the consent form with participants and provided time for women to ask any questions they had about the study and its procedures. Participants were then asked to sign their consent forms before any audio-recording equipment was turned on. 
Focus groups discussions lasted approximately 1 hour. Each focus group facilitator used a standardized discussion guide template that was tailored to each group. The discussion guide was designed in collaboration with community partner agencies to ensure relevance to the research questions and concerns of substance-using women and respectful, appropriate and accessible use of language. Questions focused on women's prior experiences of research (both good and bad), what respectful and ethical research meant to them, their reasons for taking part in research, their perspectives on informed consent, etc. Participants in all but one of the focus groups agreed to have their group discussions recorded. The BCCEW focus group was not recorded due to women's concerns that their voices were quite distinctive and therefore recognizable. In this instance, flipchart notes were taken of verbatim quotes and supplemented by field notes the facilitator made immediately after the focus group discussion.

During the focus groups, women were asked to reflect on their experiences participating in health research. They were also asked for ideas and opinions about how health research could be conducted in the future to better ensure the ethical and respectful participation of women drug-users. Women were not asked questions of a personal nature (e.g., about their individual drug use, medical conditions, criminal involvement, children, families, etc.). It was initially planned that a brief demographic questionnaire would be provided to participants in each focus group. However, in conversation with substance-using women and the partner organizations, it was decided that collecting such information from individual participants would be unwelcome. ${ }^{8}$ For these reasons, table 1 provides only a general summary of the characteristics of focus group participants, gleaned from women's responses in the focus groups and our knowledge of the communities each organization serves. Each participant was given a $\$ 20$ cash honorarium to compensate her for her time and expenses, bus tickets to subsidize the cost of travel to and from the focus group, and refreshments at the time of the focus group. Honoraria were distributed after women signed their consent forms and before the focus group discussion began.

\section{DATA ANALYSIS}

The authors and a project research assistant independently read and coded focus group transcripts. Coding was followed by a larger research team meeting to discuss and reach consensus on themes emerging from the study data. As we were primarily interested in women's articulations of what they understood to constitute ethical research, the initial analysis was primarily descriptive and focused on identifying manifest (i.e. visible, surface) themes as opposed to latent, or underlying, meanings and messages (see Kondracki, Wellman and Amundson, 2002; Graneheim and Lundman 2004). Intensive data analysis was then conducted by the first author and followed the basic guidelines of ethnographic content analysis: reflexive movement between concept development, data coding, data analysis and interpretation. Ethnographic content analysis aims to be systematic and analytic but not rigid (Altheide 1987). Like grounded theory approaches, ethnographic content analysis is embedded in constant discovery and constant comparison of relevant situations, settings, styles, images, meanings and nuances (Altheide 1987).

A description of the final themes and findings emerged after numerous reviews of the focus group transcripts. Analysis was conducted iteratively, and oriented to checking, supplementing and supplanting our original suppositions by simultaneously obtaining categorical and unique data for all the identified themes. As a central goal of this study was 
to elicit and elucidate female drug users' perceptions of ethical research, in outlining the key findings below we have preferred to use women's own words as much as possible rather than paraphrasing their statements. ${ }^{9}$

\section{Results}

\section{WHAT ETHICAL RESEARCH LOOKS LIKE (AND WHAT IT DOESN'T LOOK LIKE)}

In talking about their prior research experiences and how they would like to be engaged by researchers, a fairly consistent picture emerged from the focus group discussions. Participants criticized researchers for "acting superior" and "talking down and being condescending" (BCCEW focus group) and gave examples of being treated disrespectfully, such as being asked the same question over and over again, feeling like they were being forced to answer questions in a particular way or that the questions asked were slanted to 'prove' whatever assumptions the researcher already held about drug users. Several participants also talked about being treated like 'guinea pigs' rather than people. For example, a participant in the VANDU focus group attacked a local research study for: “...use[ing] it as a place where they're fucking basically using people as guinea pigs again, and they're not treating addicts, a lot of times, with very much respect". Similarly, a participant in the Aurora focus group observed that she wanted research participation to involve: "Something that's not demeaning, isn't condescending, doesn't make me feel like a human guinea pig because I am in addiction. I think sometimes people get the false idea that if you're in addiction then they can do whatever they want with you - that you're something to be observed". In sum, what participants wanted was to be treated "like a human being" - "with respect" (BCCEW focus group). The advice from a participant in the Watari focus group was: "Be approachable. Don't be judgmental. Hear what we have to say. Honestly listen to it”.

Many participants emphasized the importance of research that took place within a broader relationship of trust and understanding. For example, participants in the BCCEW focus group highlighted the importance of researchers approaching them through people in their network and community. A Watari focus group participant similarly commented: "I think if I went to something and someone was asking me questions I think I'd feel uncomfortable if it were just the Plain Jane professional person. It needs to be someone, like, on your levelsomeone who understands you", a theme also expressed in the Aurora focus group: "We, I guess, trust Aurora. The people here know that they're going to put it to good use so it's not a waste of time".

The need for research to be of direct benefit and value - to serve some "good use" - was a theme that came out strongly in the focus groups. Participants in the BCCEW focus group talked of negative experiences where researchers "get their degrees on our backs" and how they then "felt used and exploited because researchers don't give back to the community and give to [sex] workers". Instead, "they research violence and talk about stuff but don't give us housing or real help for drugs".

This need for research to be of concrete benefit came out particularly strongly in the following exchange at the VANDU focus group:

Participant 1: They [researchers] need to at least try and tell us why they're doing the research, and help bring up our standard of living as well. 
Participant 2: And I also think that not to give us a bullshit story about what they're going to do with the research material. A lot of times they'll have this research and surveys that they want us to be involved in, but yet when the outcome comes out it's got fuck all to do with helping us out and basically a lot of times it actually hurts us.

Women in this focus group highlighted positive experiences in prior CBR/PAR projects where they felt that the research directly benefited their community: "It was good because actually the women got asked questions and were treated respectfully and were asked questions that meant something to them, and was from them. And the research is actually, as best we can, is being used to help them".

\section{CAPACITY FOR CONSENT}

When questioned about drug users' capacity to take part in research, focus group participants expressed a variety of views. However, a consistent theme was that this was not an 'either/or' situation. Participants pointed out that the assumption that drug users had a permanently impaired capacity to consent to research was based on stereotypes and a misunderstanding of the nature and effects of drug use: "we're drug users so we're expected to be high all the time" (VANDU focus group participant). According to participants, the reality was that drug users experienced degrees of impairment depending on where they were in their drug use cycle, with a lack of wellness more likely when they were in withdrawal or "hung over" following a binge than when they were 'high'. "There's a lot of functioning for certain periods of time. I'm not going to say there's functioning addicts, but they go to work, they have their business, they own their own business and they use every day" (Aurora focus group participant). Researchers were advised to: "get to know the people in the community, participate, judge wellness case by case" (BCCEW focus group).

Another theme expressed across the groups was that even if someone was high it was problematic to exclude them from participation in research. For example, participants in the BCCEW focus group concluded that: "People that are high should be included because to exclude people is always harmful-and more harmful”. Similarly, although most participants in the VANDU focus group felt that people who were actively high should not take part in research, a participant expressed the view that "we shouldn't penalize people when they're high". Although these comments highlight the potential benefits (especially health benefits) that participants perceived from research participation, they also appeared to spring from a broader sense of the harms caused by the act of exclusion itself unsurprising when many participants have experienced such harms in the form of prejudice, discrimination and marginalization on a daily basis.

The discriminatory aspects of excluding people who were high from research participation were also highlighted in the Watari focus group, where some participants expressed the view that such people had potentially valuable insights to provide researchers:

Facilitator: Some academics have argued that people who use drugs should not be asked to participate at all. What do you think of that?

Participant 1: It's kind of true because that person could be high or coming down or whatever and totally change their mind after they get their money. They weren't thinking right at the time and they gave out information they didn't want to give out. And ya, it could definitely fall back on you guys [the researchers]. ${ }^{10}$ 
Participant 2: I disagree. I think it's kinda, if the person is high, it's kind of like discrimination. But I can understand what you're saying. There's some people that are so deep in their addiction that-

Participant 3: I think they should be allowed to do it because those people that are so deep in their addiction and stuff, they-things they have to say is valuable information, is very valuable, and-

Similarly, a participant in the Aurora focus group highlighted the potential insights into the neurobiology of addiction that could be obtained through interviewing people who were high:

Participant 7: I can easily remember how I was feeling and thinking while I was high the last time I used two months ago. And if I'm high right now and telling you these things it's not going to come out as I want them to sound. It's going to be me rambling on and probably going to get all side-tracked-

Participant 3: Yeah, that may be a positive. That's my opinion that you had-say you had a study on people that were high because you wanted to see how their brain was comprehending and when you asked questions, and then may you had them sober. I think that's very informative...

\section{REASONS FOR TAKING PART IN RESEARCH}

Although money was a central motivation for taking part in research, participants listed a variety of reasons for enrolling in studies. For example, the following exchange occurred at the VANDU focus group:

Facilitator: Why do you take part in research?

Participant 1: For the money! [General laughter]

Facilitator: That is a totally legitimate answer.

Participant 2 [to participant 1]: Don't feel bad about saying that. They're making money from the research.

Facilitator: Okay, for money, to be educated about the research.

Participant 3: Caring about our health.

Facilitator: Caring about our health.

Participant 4: Making a difference into other communities in the world-healing them. [General laughter occurs]. No, no, by why they do it—to make a difference. To make things better.

A very similar discussion occurred during the Watari focus group, where money and food were raised as key reasons for taking part in research amidst much general laughter, although one participant highlighted a desire to "help future people involved in these kind of things".

The laughter that punctuated discussions of instrumental motivations for taking part in research suggests that participants were aware that such admissions challenged the discourse of altruism that is expected to underlie research participation (Grady, 2001) - a discourse that some participants invoked themselves. However, it was clear that participants' reasons for taking part in research were multi-dimensional. Thus, the 
BCCEW focus group's discussions included statements such as: "I was sick and needed money", "better than finding money other ways", "short and easy and better than getting money the old-fashioned way" and "wanted to help towards making things better". This desire to help improve things for others was raised to varying degrees in all of the focus groups and was particularly highlighted in the following exchange in the Aurora focus group:

Participant 1: I feel that research is excellent because they can come up with a cure for addiction or come up with ways to help the addict. That's why I believe in doing research.

Participant 2: I feel it's sort of my duty in a way. I suffer from addiction and if my child was ever-had a problem-I feel that I should take part in future research.

\section{VIEWS ON FINANCIAL INCENTIVES}

The topic discussed most intensively and energetically in the focus groups was the appropriateness of financial incentives in research with drug users. In response to the question "Are there times when it is not respectful to give money?" the collective retort of participants in the BCCEW group was "Hell no!" with the group members stating: "It's disrespectful to decide for me what my money should be spent on". In the VANDU focus group participants' responses were similarly vehement, as the following exchange reveals:

Facilitator: The question is what do you think [of] people who say that you shouldn't give drug users money?

Participant 1: They're fucked up! [General chorus of agreement]

Participant 2: They are being judgmental. They are being degrading. They are looking down on us and saying 'Oh yeah, you've got money now [you'll] go and spend it on drugs', just like 'I'll buy you a sandwich but I won't give you a dollar'. But it's not-it's bullshit!

Facilitator: They're stereotyping?

Participant 2: Yeah!

Participants pointed out that how drug users choose to spend their money should not concern researchers or research ethics boards, especially given that concerns were not generally raised about how other groups spent study honoraria: "It really shouldn't matter what the person does with their money" (Watari focus group participant); "No one asks what they [researchers] do with their money and I know lots of square people that cash their checks and go buy drugs" (BCCEW focus group participant). Another similarly noted: "I think it's stereotyping... I mean, you can give the twenty dollars to someone who's not an addict and they can buy booze with it, or maybe decide to do drugs that night even if they're not addicted" (Aurora focus group participant). Alternative forms of payment such as gift cards were criticized as often being inappropriate to the circumstances of women's lives, as the following exchange at the Watari focus group demonstrates:

Participant 3: Ya, like you give out a Future Shop gift card when the person's fridge is empty. Ya (laughs). I'll fill it with a DVD.

Participant 4: Or just go get a bunch of DVDs and just go pawn them all. 
The general consensus amongst participants was that if they wanted to buy drugs they would find ways to do it regardless of whether they took part in research studies and regardless of whether they were paid in cash.

In stark contrast to the view that paying drug users was unethical, many participants stated that such payments evidenced respect for their contributions. According to one woman, "the idea, too, so many women here have been disrespected and have not been able to earn a living, just sort of that their time is being appreciated and honored and-as opposed to other things like women doing volunteer work all the time, well, why is it their time isn't deserving of getting paid for?" (Aurora focus group participant). The members of the BCCEW focus group agreed that, "I am being consulted so I should be paid like others. I am an expert in my life, even though I am economically challenged". Implicit in these statements was the idea that research participation was equivalent to paid work, and the transaction became one-sided if they were not reimbursed for their contribution - an idea that was articulated most explicitly in one participant's comment that: "They're getting paid to do the fucking research. Why can't we get paid to give them what they want!" (VANDU focus group participant).

\section{Discussion and Summary}

To some extent, the results of individual focus groups were determined by their context and composition, as the partner agencies involved in the study have different communication norms that likely influenced how women expressed themselves or framed their substance use. For example, women's language and descriptions of drug use and addiction varied substantially between the focus group held at Aurora Centre (a residential treatment program) and the one held at the headquarters of VANDU (a peer-based advocacy organization working towards harm reduction but not necessarily 'treatment'). Partner agencies also had very different experiences with research (see table 1), which affected the types of research that participants were exposed to and the prevailing norms and expectations surrounding it within each of the four settings. ${ }^{11}$ However, despite these differences, there was a high degree of consensus in all of the focus groups regarding certain key topics and issues.

Interestingly, although we expected that women in the study might express distinctively gendered views, the present study findings largely echo the results of previous research conducted with drug users, where mixed-gender studies predominate. This suggests that drug users have common research experiences, expectations and motivations that crosscut gender, although it may also be tied up with the stigmatizing nature of the 'drug addict' identity itself, with drug users engaged with as 'addicts' first, and only secondarily seen to possess ancillary characteristics such as gender.

It is clear that many women had taken part in research where they had felt degraded or dehumanized as a result of participation. Importantly, in women's discussions of their prior experiences, they often did not confine themselves to actual research studies but talked more broadly about instances of disrespect, exploitation and mistreatment by healthcare providers, police and social workers. In a number of cases, researchers were conflated with other professionals they regularly interacted with - something that has been noted in previous studies (e.g., Higgs et al. 2006: 422). 
Although this suggests some confusion about the nature of research, it also provides important insights into womens' perceptions of researchers. While researchers often see themselves as fundamentally different from other agents of intervention in drug users' lives, participants' accounts suggest that they did not so readily perceive this distinction. This indicates that existing forms of research ethics oversight have not necessarily served to make research with drug users more 'ethical' or respectful and speaks to the need for IRBs to align review processes with the expectations of people who use drugs.

Participants' accounts highlight a desire for a model of research that more closely approximates community-based research and participatory action research frameworks, where the research is community-driven, occurs in a context of trust and understanding, ${ }^{12}$ and is of direct interest and benefit to drug users themselves. Here, the comments of the BCCEW focus group participants about researchers studying phenomena such as violence but not providing housing or help for addiction, are particularly telling.

It is also clear that researchers need to be more realistic about what their research can and cannot achieve and communicate this effectively to research participants. In Barratt et al.'s (2007) study of positive and negative aspects of participation in illicit drug research, participants nominated perceived lack of impact of research findings as one of the "worst things' about drug research projects they had participated in, highlighting this as a key disincentive for future participation. Barratt et al. therefore conclude: "successful recruitment of IDU [illicit drug users] to non-intervention studies may require investigators better communicate how a study aims to influence policies and practices to the benefit of drug users and the wider community, in addition to clarification of any benefits to individual participants" (p. 237).

Women were highly critical of assertions that drug users lacked the capacity to consent to research. A consistent message across the focus groups was that assuming incapacity merely on the basis of someone's status as a drug 'addict' was stereotypical, simplistic and discriminatory. Participants insisted that capacity was a highly individual phenomenon that needed to be determined on a case-by-case basis. However, differing opinions were expressed on whether it was appropriate for people who were acutely intoxicated to take part in research, some asserting that people who were 'high' should be actively excluded and others suggesting that there were benefits to including such individuals. Interestingly, one idea that was commonly expressed (although not consistently endorsed) across all of the focus groups was that in principle exclusions of actively intoxicated individuals were discriminatory and potentially harmful. For some women, the right to take part in research was deemed to absolute - and trumped the informed consent requirements articulated in standard bioethical guidelines.

There are several reasons for taking this idea seriously. First, as noted in the introduction, much has been made of impairments in the capacity of drug users to take part in research. For example, one study of recall of research consent amongst drug court clients found that participants failed to recall over $65 \%$ of the consent information within 2 weeks of entering the study (Festinger et al., 2007). However, while this research is important in terms of empirically investigating drug users' capacity for informed consent (rather than assuming outright that such capacity is compromised), it also relies on an ideal model of informed consent whereby the participants' and researchers' understandings of the study overlap completely. In this model, understandings that deviate from those promulgated in the study 
materials are seen to represent a 'failure' on the part of participants to correctly identify the study goals and procedures or 'deficiencies' in the process of information disclosure or design (Dixon-Woods et al., 2007).

Based on interviews conducted with healthy subjects who had recently taken part in a genetic study, Dixon-Woods et al. (2007) found similar 'deficits' in their recall of study goals; indeed, many participants' understandings directly contradicted the stated study goals. Dixon-Woods et al.'s research therefore suggests that the much-touted 'deficits' in the capacities of drug users are not unique to this population. Rather, there may be a "persistent and incorrigible disconnect" between researchers' and participants' perceptions of research. As Dixon-Woods et al. (2007) note, differences between lay and scientific understandings are well documented in other contexts, so it should not be assumed that research participation is any different.

We therefore suggest that the present focus on drug users' capacity to participate in research may well be misplaced (see also Carter \& Hall, 2008 and Fisher, 2011 for similar points). If the emphasis instead shifted to the broader principle of inclusivity, the focus would then be on finding ways to include drug users that support their capacity to provide consent. This would require a view of consent as an ongoing and dynamic process with particular attention paid to ensuring rights to withdraw consent after participation, and a greater emphasis on alternative forms of consent beyond the traditional written consent form, such as video or multi-media presentations of study goals and consent information (Festinger et al., 2007). In light of the well established contrasts between lay and scientific knowledge, it would also require a recognition that it is possible for legitimate decisions to be made about participation that do not require a full understanding and acceptance of the scientific account of a research study (Dixon-Woods et al., 2007). This is not to suggest that understanding does not matter. As Dixon-Woods et al. note, "while it is not always necessary for participants' accounts of their reasons and understanding to be identical to the scientific/ethical account in order for them to make a legitimate decision about participation, it is important to identify where a mistaken belief would threaten legitimacy" (p. 2220).

The legitimacy accorded to participants' decisions would need to extend to drug users' motivations for taking part in research, which also differ from those that institutional review boards tend to prioritize (Dixon-Woods et al., 2007). As prior empirical research into this topic has found (see Fry \& Dwyer, 2001; Barratt et al., 2007), while financial motivations do play a role - often a very important one - in drug users' decisions to take part in research, they ultimately do so for a variety of reasons, including perceived benefits for others (e.g. altruism, activism) as well as themselves. In this respect, drug users differ little from members of the broader population (see also Striley 2011 for similar points). According to Grady (2001: 41), the complexity of human motivation is such that people rarely have a single reason for doing things; thus, "being attracted to the money offered for research participation does not necessarily negate the possibility of other influential motivations and considerations".

Fry, Ritter and their colleagues (Ritter et al., 2003; Fry et al., 2006) argue that paying drug users for research participation constitutes 'fair reimbursement': a pragmatic means of acknowledging the time and expertise of participants who otherwise have no meaningful ownership of research results. Similarly, when we asked women about what they thought of 
such payments, they expressed their views in no uncertain terms: money was not only not an undue inducement, it was seen to be an ethical and respectful acknowledgement of their time and expertise (see also Salmon, Browne \& Pederson, 2010). As they pointed out, researchers were paid by their institutions to conduct the research, and so they should be paid to take part in it - the money in some respects served to equalize an otherwise highly imbalanced exchange.

In this respect, our findings closely echo those of Slomka et al. (2007), who asked male and female African-American drug users enrolled in HIV studies to similarly reflect on the ethics of offering financial incentives. Like women enrolled in our study, participants strongly endorsed the idea that drug users who take part in research should be paid. They did not see payment as exploitative, but as acknowledging a mutual exchange - "they're helping you and you're helping them" (p. 1406). Participants also pointed out that the money alone was not incentive enough to take part in research studies. Like the women in our study, they noted that while payments might be spent on drugs, this was not their sole reason for taking part in research, because they could always obtain drugs through other means.

Further support for these findings is provided by Festinger et al.'s (2005) research into the impact of payments on research participation amongst male and female drug users. In this study, 350 outpatients in an addictions treatment program were randomly assigned to payments of $\$ 10, \$ 40$ or $\$ 70$ in either cash or gift certificates for participating in a 6 -month follow-up research assessment. They found that cash payments did not have a significant impact on participants' drug use or their perceptions of the coerciveness of the research, although higher cash amounts did improve study retention. Moreover, in a related study conducted by Festinger et al. (2009), they found that payments were associated with higher comprehension (and retention) of consent forms.

Our study suggests that research participation is a part of the informal economy in economically disadvantaged communities and provides drug users with an additional source of income that is potentially less hazardous than other ways of obtaining money (see also Slomka et al., 2007), which for women in our study primarily took the form of sex work (or "earning money the old fashioned way", as women referred to it). We therefore disagree with Fry et al.'s (2006) recommendation that references to payment and inclusion and exclusion criteria be removed from study recruitment advertisements - at least in the context of non-intervention studies, where the risks and benefits of research participation are substantially reduced. Intentionally obscuring information that is important to drug users (even if it does not constitute the sole factor in their decision making) may serve to waste people's time, as they are then forced to follow up about studies they may not actually be eligible to or interested in participating in.

Overall, our findings suggest that current notions of 'vulnerability' require reconsideration. As several observers have noted, the concept as it has been imported into research ethics is both too broad and too narrow: it stereotypes whole categories of individuals and diverts attention away from features of research projects and their environments that might positively or negatively affect participants (Levine et al., 2004; Henderson, Davis \& King, 2004). Although researchers and institutional review boards cannot mitigate the stigma and marginalization that many drug users struggling with addiction encounter in their everyday lives, they can do their best to ensure that research does not exacerbate these 
harms. Listening to what drug users have to say, and recognizing the differences in their positioning based on factors such as gender, class and ethnicity, is critical.

\section{STUDY LIMITATIONS}

While the findings presented in this article were gathered and analyzed using methods to ensure results are accurate, valid and reliable, they are not intended to be generalizable to all female drug users, or drug users more broadly. First, although we were able to recruit a diverse range of women with substance use issues (e.g., sex workers, young women, women in treatment for addiction, women not currently seeking treatment for substance use), the overall number of women recruited into the study was small and may not reflect the experiences of female drug users more broadly. Second, as the majority of women in our study had taken part in nonintervention studies, it is unclear how readily our findings apply to clinical research with female drug users.

A final word of caution is needed in interpreting our study findings. There is a possibility that our study design influenced the results we obtained. For example, as we provided a nominal honorarium, our study may have attracted women who were more likely to view such payments positively. Similarly, the CBR/PAR framework of our study may have attracted participants who prefer this model of research, thereby prefiguring the support for such frameworks expressed by participants.

TABLE 2. Questions institutional review boards might consider when reviewing applications involving research with female drug users

1. Do the individuals who will be interacting with research participants (e.g., recruiting, obtaining informed consent, collecting data) demonstrate adequate familiarity with the community under study and patterns of drug use?

While the principal investigators on a study may be experienced addictions researchers, review boards should pay attention to the personnel directly involved in implementation of the study and their experience in conducting research with this population.

\section{Is there evidence of engagement and consultation with the drug-user community being} studied?

Engagement with drug using communities may not be a feasible requirement for all research with drug users, but evidence of such engagement in terms of the study design is likely to mean that the resulting study has considered ethical issues from the point of view of community members and is less likely to be perceived as demeaning or disrespectful. Evidence of consultation regarding the sorts of feedback participants and their communities are looking for and clear mechanisms to disseminate the study results to the community in an appropriate form should also be encouraged.

3. How is capacity being assessed and how often?

Capacity should be assessed on a case-by-case basis. It is important for review boards to be aware that many so-called 'addicts' do not use to get 'high' but to stave off withdrawal. Viewed in this way, people are potentially more impaired when they are withdrawing than when they are 'high' (Nahas, 1991).

\section{How is consent being obtained?}


Review boards should be open to a variety of methods of obtaining consent beyond the traditional signed consent form (e.g., community or multi-media presentations that include an extensive Q\&A period, oral consent). It may be appropriate for presentations of study information to take place separately from consent processes and data collection.

\section{How are the study benefits framed?}

In view of participants' concerns that studies often fail to help their communities and waste their time (see also Barratt et al., 2007), researchers should ask themselves: do the study materials provide a realistic assessment of what might be accomplished from the study? It is critical that investigators realistically present the potential results of their studies and don't 'overpromise' in terms of what their research might achieve.

6. Does the research involve a clinical intervention or is it an observational study?

Given the differing risks that clinical research and observational studies entail, they should not necessarily be held to the same standards - especially in relation to subject payments. Researchers should be allowed to disclose payment amounts in recruitment materials for non-clinical studies as these payments represent a legitimate incentive for participation and our study and prior research suggest that this information is important to drug users.

7. How does the payment compare with other sources of income drug users have access to? In light of our findings and those of prior researchers (e.g., Slomka et al., 2007) that research participation provides an additional source of income for drug users, rather than focusing exclusively on the dollar amount of the payment itself, we suggest that research ethics boards should consider the time commitment required of participants in relation to the amount provided. If the hourly breakdown is consistent with other income sources participants have access to, payments should not be considered undue inducements.

\section{Best Practices}

As Fry et al. (2006: 32) have previously stated, "Research participants who use and who may be dependent on drugs deserve the same ethical protections and choices during research as other participant groups". Institutional review boards should therefore be careful not to make assumptions about the capacity of drug users to participate in research, or the (in)appropriateness of monetary payments to this population. In light of the current dearth of research into drug users' views on ethical research, it is clearly too early to identify 'best practices' in this area. Moreover, as Fisher (2011: 737) notes, resolving ethical dilemmas in addictions research is "a reflective, contextually and relationally based endeavor, with no cookie cutter answers". However, based on our study findings we have crafted some questions that may help review boards in their deliberations about research involving female drug users (see table 2), although we recognize that they are likely to be relevant for considerations of drug use research more broadly. These questions should not be taken as prescriptions for how research should proceed, but may help review boards to be more cognizant of the ethical issues that women drug users themselves identify as important.

\section{Research Agenda}

Clearly, there is a critical need for further empirical studies asking drug users how they would like to be engaged in research. Guidelines for ethical research with drug users should be informed by research with members of this population. Although our study suggests that 
the perspectives of female drug users generally cohere with those of drug users more broadly, it is also important that research moves beyond representations of 'drug users' as a homogeneous category and more explicitly considers the impact of gender, but also other factors such as class background and ethnicity, on people's experiences and their views on what constitutes ethical research practice.

It is also time that the debate moves beyond the question of whether nor not drug users have the capacity to provide informed consent to participate in research. Instead, further research is needed on how to enhance consent processes and decision-making capacities (Festinger et al., 2007). Studies examining multi-media presentations have yielded promising results (Anderson \& DuBois, 2007; Festinger et al., 2007), but further research is clearly needed. Finally, further qualitative research into drug users' motivations for taking part in research and their views on financial incentives would also be useful (Ritter et al., 2003)

Future studies should also be careful to distinguish between clinical and non-intervention studies when exploring the ethics of research with drug users, rather than assuming that general ethical recommendations can be created that encompass all study types. In light of the very different types of risks and benefits that these studies entail, financial incentives and capacity issues may be less of a concern in social science than in clinical research. Indeed, as numerous critics of the institutional ethics review model have pointed out, the unquestioning transposition of ethical principles from clinical and biomedical research to social science research has led to inappropriate practices that may actually encourage less ethical practice (see Schrag 2010).

\section{Acknowledgments}

The authors wish to thank Lorraine Greaves, Michele Bowers, Lori D'Agincourt-Canning, Bethan Everett, Deborah Rutman, Marilyn Van Bibber, Nancy Poole, Raven Bowen, Laurel Dykstra, Trica McDiarmid, Julie Ham, and Lisa Fielding for their contributions to this study as co-investigators, collaborators, and research assistants. We gratefully acknowledge the funding provided to this study by the Canadian Institutes of Health Research through an Ethics Office Seed Grant and Knowledge Translation Supplement Grant.

\section{Notes}

1 Also known as research ethics boards and research ethics committees.

2 Special protections may include a requirement that research conducted with vulnerable populations pose no greater than 'minimal risk', involve the prospect of direct benefit to the participants, incorporate 'enhanced' consent procedures (e.g. third party authorization), etc.

3 Although this is often a topic that is of paramount importance to drug users themselves, it is less intensively discussed than capacity issues and financial incentives - perhaps because it is an area that relates more to researchers' practices than drug users' characteristics.

4 Drug users in Vancouver, especially those living in the Downtown Eastside (DTES), an area of the city with a notorious reputation as 'Canada's poorest postal code' and 'the epicenter of the city's open-air drug market', are a highly researched population. Indeed, many DTES residents and front-line service providers frequently remark that people who 
use drugs have been 'researched to death'.

5 Nineteen is the age of majority in the province of British Columbia. Research Ethics Boards therefore generally require that parental consent be obtained for research conducted with participants under this age.

6 While there are pros and cons to having a facilitator with an existing relationship with focus group participants, the research team has previously found that focus groups tended to yield more information and participants perceived a better environment for discussion when facilitators were previously known to them (a view that was borne out by the study data itself).

7 The focus group facilitator asked what research women had been involved in and provided examples of various types of research, e.g., "some research involves having people fill out questionnaires on paper, interviewing people on the phone, face-to-face, or in focus groups"; "some research involves asking people to participate in clinical trials of a drug or therapy, or to give samples of things like blood or hair"; "community agencies also often ask people who access their services to participate in evaluations of their program". Women that the focus group facilitator felt did not have research experience were screened out at this stage.

8 It was felt that collecting this information would contradict our assurances to women that we were interested in their research experiences rather than their personal histories (including prior drug use) and could potentially heighten women's concerns about confidentiality and anonymity.

9 Neale et al. (2005) in an article on qualitative research in addictions have argued that there is a tendency to over-rely on the use of quotations and that this evidences a less-thanrigorous analysis. We think absolute statements along these lines are problematic and suggest that in research whose purpose is to describe the views of drug users, direct quotations may be more appropriate than paraphrasing.

10 It is interesting that the participant here focused on the implications of intoxication for the researchers rather than the subject - something that also came out in discussions at other focus groups. Such statements imply that women were concerned about the 'ethics' of research not merely in relation to the researchers' actions, but also those of research participants. This echoes previous findings of previous research with drug users (Fisher, 2011) and research participants more broadly (Cox, McDonald \& Hancock, 2010), where ethical responsibilities are seen to apply to both researchers and participants.

11 For example, VANDU regularly partners with researchers, and has a Scientific Advisory Committee composed almost exclusively of allied researchers. Similarly, BCCEW has produced its own guidance on ethical research with sex workers, and has regular discussions with its members about this issue.

12 Trusting relationships have been previously found to be an important ingredient for conducting research with drug users (see Higgs et al., 2006; Salmon, Browne \& Pederson, 2010).

\section{References}

Altheide, D.L. (1987). Ethnographic content analysis. Qualitative Sociology, 10(1), 65-77.

Anderson, E.E. \& DuBois, J.M. (2007). The need for evidence-based research ethics: a review of the substance abuse literature. Drug \& Alcohol Dependence, 86, 85-105.

Banwell, C., \& Bammer, G. (2006) Maternal habits: Narratives of mothering, social position 
and drug use. International Journal of Drug Policy, 17(6), 504-13.

Barratt, M.J., Norman, J.S., \& Fry, C.L. (2007). Positive and negative aspects of participation in illicit drug research: Implications for recruitment and ethical conduct. International Journal of Drug Policy, 18, 235-238.

Boyd, C.J. (1993) The antecedents of women's crack cocaine abuse: Family substance abuse, sexual abuse, depression and illicit drug use. Journal of Substance Abuse Treatment, 10(5), 433-438.

Buchanan, D., Khoshnood, K., Stopka, T., Shaw, S., Santelices, C., \& Singer, M. (2002). Ethical dilemmas created by criminalization of status behaviors: Case examples from ethnographic field research with injection drug users. Health Education \& Behavior, 29(1), 30-42.

Burris, S. \& Moss, K. (2006). U.S. health researchers review their ethics review boards: a qualitative study. Journal of Empirical Research on Human Research Ethics: an International Journal, 1(2), 39-58.

Busche, G.R. (1998). Appreciative inquiry with teams. Organizational Development. 19(3), 41-49.

Campbell, N. (2000) Using Women: Gender, Drug Policy, and Social Justice. London: Routledge.

Canadian Institutes of Health Research, Natural Sciences and Engineering Research Council of Canada, and Social Sciences and Humanities Research Council of Canada (2010) Tri Council Policy Statement: Ethical Conduct for Research Involving Humans. Second Edition. Canada: Interagency Panel on Research Ethics.

Carter, A., \& Hall, W. (2008). The issue of consent in research that administers drugs of addiction to addicted persons. Accountability in Research, 14(4), 209-25.

Chambers, T. (2001) Participation as commodity, participation as gift. American Journal of Bioethics, 1(2), 48.

Cohen, P.J. (2002). Untreated addiction imposes an ethical Bar to recruiting addicts for non-therapeutic studies of addictive drugs. Journal of Law, Medicine \& Ethics, 30, 73-81.

Cox, S.M., McDonald, M., \& Hancock, S. (2010). 'Ethics is for human subjects too': Understanding participant perspectives on responsibility in health research. Public Responsibility in Medicine and Research Conference, San Diego (December 5-8, 2010).

Dixon-Woods, M., Ashcroft, R.E., Jackson, C.J., Tobin, M.D., Kivits, J., Burton, P.R., \& Samani, N.J. (2007) Beyond "misunderstanding": Written information and decisions about taking part in a genetic epidemiology study. Social Science \& Medicine, 65, 22122222.

Festinger, D.S., Marlow, D.B., Croft, J.R., Dugosh, K.L., Arabia, P.L., \& Benasutti, K.M. (2009). Monetary incentives improve recall of research consent information: it pays to remember. Experimental \& Clinical Psychopharmacology, 17, 99-104.

Festinger, D.S., Marlowe, D.B., Croft, J.R., Dugosh, K.L., Mastro, N.K., Lee, P.A., DeMatteo, D.S., Patapis, N.S. (2005) Do research payments precipitate drug use or coerce participation? Drug \& Alcohol Review, 78(3), 275-281.

Festinger, D.S., Ratanadilok, K., Marlowe, D.B., Dugosh, K.L., Patapis, N.S., \& DeMatteo, D.S. (2007). Neuropsychological functioning and recall of research consent information among drug court clients. Ethics \& Behavior, 17(2): 163-186.

Fisher, C.B. (2004). Ethics in drug abuse and related HIV risk research. Applied Developmental Science, 8(2), 91-103. 
Fisher, C.B. (2011). Addiction research ethics and the Belmont principles: Do drug users have a different moral voice? Substance Use \& Misuse, 46, 728-741.

Fry, C. \& Dwyer, R. (2001). For love or money? An exploratory study of why injecting drug users participate in research. Addiction, 96, 1319-1325.

Fry, C.L., Hall, W., Ritter, A., \& Jenkinson, R. (2006). The ethics of paying drug users who participate in research: a review and practical recommendations. Journal of Empirical Research on Human Research Ethics: an International Journal, 1(4), 21-36.

Fry, C.L., Ritter, A., Baldwin, S., Bowen, K.J., Gardiner, P., Holt, T., Jenkinson, R., \& Johnston, J. (2005). Paying research participants: a study of current practices in Australia. Journal of Medical Ethics, 31, 542-547.

Fullilove, M.T., Fullilove, R.E., Smith, M., Winkler, K., Michael, C., Panzer, P.G. \& Wallace, R. (193) Violence, trauma, and post-traumatic stress disorder among women drug users. Journal of Truamatic Stress, 6(4), 533-543.

Grady, C. (2001). Money for research participation: Does it jeopardize informed consent? American Journal of Bioethics, 1(2), 40-44.

Graneheim, U.H. \& Lundman, B. (2004). Qualitative content analysis in nursing research: Concepts, procedures and measures to achieve trustworthiness. Nurse Education Today, 24, 105-112.

Harrison, K. \& J. Barlow (1995). Focused group discussion: A 'quality' method for health research? Health Psychology Update 20, 11-13.

Henderson, G.E., Davis, A.M., \& King, N.M.P. (2004). Vulnerability to influence: a two-way street. American Journal of Bioethics, 4(3), 50-52.

Higgs, P., Moore, D., \& Aitken, C. (2006). Engagement, reciprocity and advocacy: ethical harm reduction practice in research with injecting drug users. Drug \& Alcohol Review, 25, 419-423.

Kitzinger, J. (1994). The methodology of focus groups: The importance of interaction between research participants. Sociology of Health \& Illness, 16(1), 103-21.

Kondracki, N.L., Wellman, N.S., \& Amundson, D.R. (2002). Content analysis: Review of methods and their applications in nutrition education. Journal of Nutrition Education and Behaviour, 34(4), 224-230.

Krieger, N. (2003) Gender, sexes, and health: What are the connections and why does it matter? International Journal of Epidemiology, 32, 652-657.

Lam, W.K.K., Wechsberg, W. \& Zule, W. (2004) African-American women who use crack cocaine: a comparison of mothers who live with and have been separated from their children. Child Abuse \& Neglect, 28(11), 1229-1247.

Lemmens, T. \& Elliot, C. (1999) Guinea pigs on the payroll: the ethics of paying reearch subjects. Accountability in Research, 7(1), 3-20.

Levine, C., Faden, R., Grady, C., Hammerschmidt, D., Eckenwiler, L., \& Sugarman, J. (2004). The limitations of 'vulnerability' as a protection for human research participants. American Journal of Bioethics, 4(3), 44-49.

Loue, S. \& Ioan, B. (2007). Legal and ethical issues in heroin diagnosis, treatment, and research. Journal of Legal Medicine, 28(2), 193-221.

Maher, L. (1997) Sexed Work: Gender, Race and Resistance in a Brooklyn Drug Market. New York: Clarendon Press.

McCrady, B.S. \& Bux, D.A. (1999). Ethical issues in informed consent with substance users. Journal of Consulting \& Clinical Psychology, 67(2), 186-193. 
Medrano, M.A., Zule, W.A., Hatch, J. \& Desmond, D.P. (1999) Prevalence of childhood trauma in a community sample of substance-using women. American Journal of Drug and Alcohol Abuse, 25(3), 449-462.

Miller, J. (1995) Gender and power on the streets: Street prostitution in the era of crack cocaine. Journal of Contemporary Ethnography, 23(4), 427-452.

Moreno, J.D. (2001). It's not about the money. American Journal of Bioethics, 1(2), 46.

Nahas, G.G. (1991). Drugs, the brain, and the law. Notre Dame Journal of Law, Ethics \& Public Policy, 5(4), 729-746.

Najavits, L.M., Weiss, R.D. \& Shaw, S.R. (1997) The link between substance abuse and posttraumatic stress disorder in women. American Journal on Addictions, 6(4), 273-283.

Neale, J., Allen, D., \& Coombes, L. (2005). Qualitative research methods within the addictions. Addiction, 100, 1584-1593.

Office for Human Research Protections (2009). Code of Federal Regulations: Title 45 Human Welfare. Part 46 Protection of Human Subjects. Washington, DC: US Department of Health \& Human Services.

Ristock, J.L., \& Pennell, J. (1996). Community Research as Empowerment: Feminist Links, Postmodern Interruptions. Oxford University Press: Toronto.

Ritter, A.J., Fry, C.L., \& Swan, A. (2003). The ethics of reimbursing injecting drug users for public health research interviews: what price are we prepared to pay? International Journal of Drug Policy, 14, 1-3.

Salmon, A., Poole, N., Morrow, M., Greaves, L., Ingram, R. \& Pederson, A. (2006) Integrating Sex and Gender into Federal Mental Health and Addictions Policy. Vancouver, BC: British Columbia Centre of Excellence for Women's Health.

Salmon, A. (2007). Walking the talk: How participatory interview methods can democratize research. Qualitative Health Research, 17(7), 982-993.

Salmon, A., Browne, A., \& Pederson, A. (2010). 'Now we call it research': Participatory health research involving marginalized women who use drugs. Nursing Inquiry, 17(4), 336-345.

Seddon, T. (2005). Paying drug users to take part in research: Justice, human rights and business perspectives on the use of incentive payments. Addiction Research \& Theory, 13(2), 101-109.

Shrag, Z. (2010). Ethical Imperialism: Institutional Review Boards and the Social Sciences, 1965-2009. Baltimore, MD: Johns Hopkins University Press.

Slomka, J., McCurdy, S., Ratliff, E.A., Timpson, S., \& Williams, M.L. (2007). Perceptions of financial payment for research participation among African-American drug users in HIV studies. Journal of General Internal Medicine, 22(10), 1403-9.

Striley, C.W. (2011). A review of current ethical concerns and challenges in substance use disorder research. Current Opinion in Psychiatry, 24, 186-90.

Todd, C (2001). Research participation and financial inducements. American Journal of Bioethics, 1(2), 60-61.

Vanderpool, H.Y. (2001) Payments to participants: Beware of Trojan Horses. American Journal of Bioethics, 1(2), 58-60.

Wilkinson, S. (1998). Groups in feminist research: Power, interaction, and the coconstruction of meaning. Women's Studies International Forum, 21(1), 111-25. 